\title{
Species-specific duplications driving the recent expansion of NBS-LRR genes in five Rosaceae species
}

\author{
Yan Zhong ${ }^{1}$, Huan Yin ${ }^{1}$, Daniel James Sargent ${ }^{2}$, Mickael Malnoy ${ }^{2}$ and Zong-Ming (Max) Cheng ${ }^{1,3^{*}}$
}

\begin{abstract}
Background: Disease resistance $(R)$ genes from different Rosaceae species have been identified by map-based cloning for resistance breeding. However, there are few reports describing the pattern of $R$-gene evolution in Rosaceae species because several Rosaceae genome sequences have only recently become available.

Results: Since most disease resistance genes encode NBS-LRR proteins, we performed a systematic genome-wide survey of NBS-LRR genes between five Rosaceae species, namely Fragaria vesca (strawberry), Malus $\times$ domestica (apple), Pyrus bretschneideri (pear), Prunus persica (peach) and Prunus mume (mei) which contained 144, 748, 469, 354 and 352 NBS-LRR genes, respectively. A high proportion of multi-genes and similar Ks peaks $(K s=0.1-0.2)$ of gene families in the four woody genomes were detected. A total of 385 species-specific duplicate clades were observed in the phylogenetic tree constructed using all 2067 NBS-LRR genes. High percentages of NBS-LRR genes derived from species-specific duplication were found among the five genomes (61.81\% in strawberry, $66.04 \%$ in apple, $48.61 \%$ in pear, $37.01 \%$ in peach and $40.05 \%$ in mei). Furthermore, the $K s$ and $K a / K s$ values of TIR-NBS-LRR genes (TNLs) were significantly greater than those of non-TIR-NBS-LRR genes (non-TNLs), and most of the NBS-LRRs had $\mathrm{Ka} / \mathrm{Ks}$ ratios less than 1 , suggesting that they were evolving under a subfunctionalization model driven by purifying selection.

Conclusions: Our results indicate that recent duplications played an important role in the evolution of NBS-LRR genes in the four woody perennial Rosaceae species. Based on the phylogenetic tree produced, it could be inferred that species-specific duplication has mainly contributed to the expansion of NBS-LRR genes in the five Rosaceae species. In addition, the Ks and Ka/Ks ratios suggest that the rapidly evolved TNLs have different evolutionary patterns to adapt to different pathogens compared with non-TNL resistant genes.
\end{abstract}

Keywords: NBS-LRR genes, Rosaceae species, Disease resistance genes, Species-specific duplication

\section{Background}

Plants are under constant challenge from a diverse array of pathogens, including bacteria, fungi, oomycetes, viruses and nematodes [1]. Due to high selective pressures, plants have evolved a series of mechanisms to recognize and defend themselves against such pathogens [1,2]. Plant disease resistance $(R)$ genes play an important role in pathogen detection and defense response, and are classified into five types, namely NBS-LRR (Nucleotide Binding Sites-

\footnotetext{
* Correspondence: zmc@njau.edu.cn

'College of Horticulture, Nanjing Agricultural University, Nanjing 210095, China

${ }^{3}$ Department of Plant Science, University of Tennessee, Knoxville 37996, USA Full list of author information is available at the end of the article
}

Leucine-Rich Repeats), RLK (Receptor-like Kinases), RLP (Receptor-like Transmembrane Proteins), STK (Serinetheorine kinase) and a final category containing all other types of $R$ gene. The NBS-LRR genes, encoding nucleotide binding sites (NBS) and leucine-rich repeats (LRR) proteins, are one of the largest plant $R$-gene classes. The NBS domains bind and hydrolyze ATP and GTP, and the LRR motif is involved in protein-protein interactions and pathogen recognition specificity [3]. NBS-LRR proteins can be further sub-divided into two types based on their $\mathrm{N}$-terminal amino acid sequences, TIR-NBS-LRR containing a Toll/Interleukin-1 receptor domain and non-TIRNBS-LRR genes which contain a coiled-coil (CC), or leucine zipper motif [4]. 
The major function of NBS-LRR genes is disease resistance through pathogen recognition [1,2]. Patterns of rapid $R$-gene evolution could help host plants recognize avirulence genes and activate downstream transduction cascades, leading to defense responses, hypersensitive reactions and programmed cell death [1]. Abundant NBS-LRR genes have been identified in various plants, e.g. Arabidopsis, Medicago, Vitis (grapevine), Populus (poplar), Oryza sativa (rice) and Zea mays (maize) [5-9]. Interestingly, distinct numbers of NBS-LRR genes were found among these species [5-9]. Since all plant $R$-genes are assumed to have originated from one common ancestor [10], the various gene numbers might therefore be derived from gene duplications in a given species. Recent studies have shown that the NBS gene family possesses a higher proportion of duplicate genes than other gene families $[8,11]$. The rapid gene expansion or contraction of this family might therefore be a survival strategy to combat rapidly-evolving, species-specific pathogens $[6,8]$.

The Rosaceae family is an economically-important family throughout the world, and comprises many important fruits, such as strawberries, apples, pears, peaches, meis and apricots, as well as flowers and ornamental trees such as roses and rowans [12]. Various pathogens infect these plants leading to a variety of crop diseases, such as powdery mildew, scab, fire blight and sharka disease. Serious economic losses from such pathogens have highlighted the necessity of disease resistance breeding in Rosaceae crops [13,14], and as such the $R$-genes from many members of the Rosaceae family have previously been studied for the purposes of resistance breeding [13-17]. Nevertheless, classic genetic analysis is difficult on Rosaceae species, because many of them are woody perennial plants with a long intergeneration time and a large plant size. Although some powdery mildew, scab and fire blight resistance genes have been identified and mapped in various Rosaceae species, such as the apple scab resistance gene Rvil5/Vr2 encoding TNL proteins, and a fire blight resistance gene encoding CNL protein in Malus $\times$ robusta [18-27], a genome-wide analysis of Rosacese $R$-genes would permit the identification of additional resistance genes for marker-assisted selection.

The recent completion of genome sequences of the woodland strawberry (F. vesca) [28], apple ( $M . \times$ domestica) [29], Asian pear (P. bretschneideri) [30], peach (P. persica) [31] and mei (P. mume) [32] provides the opportunity to study the evolution of NBS-LRR genes between five Rosaceae genomes. In this work, various numbers of genes and gene families were identified across the five species. Subsequently, different evolutionary patterns of TNL genes and non-TNL genes were observed. Our results suggest that recent, species-specific duplications may have contributed to the rapid expansion of NBS-LRR genes in these species.

\section{Results}

\section{NBS-LRR genes in five Rosaceae species}

A total of 144, 748, 469, 354 and 352 NBS-LRR genes were detected in the F. vesca, M. × domestica, P. bretsvhnrideri, $P$. persica and $P$. mume, genomes, respectively (Table 1). All Rosaceae species contained more non-TIRNBS-LRR genes (non-TNLs) than TIR-NBS-LRR genes (TNLs) (Table 1). However, unlike non-TLNs, the proportion of TNLs in strawberry (15.97\%) was lower than those in the other four species $(29.28 \%$ in apple, $47.12 \%$ in pear, $36.16 \%$ in peach and $43.47 \%$ in mei, Table 1 ). Non-TNLs were further classified into CC-NBS-LRR (CNL) and X-NBS-LRR (XNL) genes, and similar gene numbers for each class were observed in the five species, except in pear. In terms of the relative proportions of the different R-gene classes in the five genomes, the same smallest and largest relative values were found in the strawberry and apple genome, respectively (Table 1).

The mean number of exons revealed in NBS-LRR genes was 4.86 in strawberry, 5.2 in apple, 4.81 in pear, 4.18 in peach and 4.52 in mei. The average exons were lower than observed for all predicted genes in strawberry, peach and mei, but greater than those observed in apple and pear. The average exon number of TNLs was greater than those in non-TNLs in the genomes of all five species, consistent with observations made in the grape and poplar genomes [7], and 1.04-, 1.58-, 1.74-, 1.98-, 2.15-fold were detected between the average exon numbers of TNLs and non-TNLs in strawberry, apple, pear, peach and mei, respectively.

Gene families of NBS-LRR genes in five Rosaceae fruit species Gene duplication have contributed to the high numbers and proportions of NBS-LRR genes in plant families [33]. To explore the duplications in the five Rosaceae species examined here, gene families were defined and detected based on two criteria (Table 2: coverage $>70 \%$ and identity $>70 \%$ ). The greatest and smallest numbers of gene families were found in apple (107) and strawberry (12), respectively. Accordingly, the four woody species possessed greater proportions of multi-NBS-LRR-genes than strawberry (32.64\%) which is the only herbaceous plant represented by the five species. In apple (68.98\%), pear $(63.33 \%)$ and peach $(65.82 \%)$, the proportions of multi-genes comprised over $50 \%$ of total NBS-LRR genes in each genome. Using more stringent criteria (>80\%) as the measurement for recent duplication, the proportions of multi-genes observed decreased by around $10 \%$ compared with that resulted from the less stringent standard (>70\%) among all five genomes (Additional file 1: Table S1), but in apple, pear and peach, the proportions 
Table 1 The NBS-LRRs in genomes of five Rosaceae fruit species

\begin{tabular}{llllll}
\hline Predicted protein domains & Fragaria vesca & Malus domestica & Pyrus bretschneideri & Prunus persica & Prunus mume \\
\hline NBS-LRR genes & $\mathbf{1 4 4}$ & $\mathbf{7 4 8}$ & $\mathbf{4 6 9}$ & $\mathbf{3 5 4}$ & $\mathbf{3 5 2}$ \\
TIR-NBS-LRR & $23(15.97 \%)$ & $219(29.28 \%)$ & $221(47.12 \%)$ & $128(36.16 \%)$ & $153(43.47 \%)$ \\
non-TIR-NBS-LRR & $121(84.03 \%)$ & $529(70.72 \%)$ & $248(52.88 \%)$ & $226(63.84 \%)$ & $199(56.53 \%)$ \\
CC-NBS-LRR & 60 & 243 & 160 & 108 & 99 \\
X-NBS-LRR & 61 & 286 & 88 & 118 & 100 \\
Whole genome genes & 32831 & 57386 & 42767 & 27852 & 31390 \\
Proportion of NBS-LRR genes & $0.44 \%$ & $1.30 \%$ & $1.10 \%$ & $1.27 \%$ & $1.12 \%$ \\
Average exon no. of TIR-NBS-LRR & 5.04 & 7.01 & 6.21 & 6.11 & 3.48 \\
Average exon no. of non-TIR-NBS-LRR & 4.83 & 4.45 & 3.57 & 4.18 & 3.02 \\
Average exon no. of NBS-LRR genes & 4.86 & 5.2 & 4.81 & 4.97 & 4.52 \\
Average exon no. of all genes & 5.09 & 4.74 & 4.7 & 4.6 \\
\hline
\end{tabular}

were still in excess of $50 \%$. However, when the most stringent criteria $(>90 \%)$ were used, the proportions of multigenes reduced significantly in all five species (Wilcoxon signed ranks test, $P<0.05)$.

Additionally, non-TNLs were more abundant in each species than TNLs and were present in largest numbers in both multi-genes and gene families (Table 1). The proportion of multi-genes in both non-TNLs and TNLs corresponded with the data observed for NBS-LRR genes in the five species. However, the number of gene families and the proportion of multi-genes between the two types of NBS-LRR genes were distinct between the different genomes; non-TNLs displayed lower proportions of multi-genes than TNLs in strawberry, peach and mei, whereas larger proportions were found in apple and pear, consistent with the closely evolutionary relationship between the latter two species. Therefore, the results suggested that non-TNLs have undergone more recent duplication than TNLs in the two Maloideae species, apple and pear. From various perspectives, NBS-
LRR genes showed distinct duplication history not only in different species but also in different gene types.

\section{Evolutionary history of NBS-LRR genes in five Rosaceae fruit species}

The $K s$ value is commonly used as molecular clock to measure the time elapsed since gene duplication [34]. To explore the duplication time of NBS-LRRs in each of the five genomes, the average $K s$ value of each gene family (Table 2) was calculated. $K s$ values exhibited continuous distribution in all five genomes, suggesting NBS-LRR gene duplication is an ongoing process in each species. However, the distribution of $K s$ was distinctly different among five species, especially between the herbaceous strawberry (Figure 1A) and the four ligneous plants (Figure 1B-E). The relatively even distribution of $K s$ values at the range of 0 to 0.4 with a slight peak at 0.3 to 0.4 in strawberry genome suggests that duplication events have been a relatively constant process. The $K s$ values in the four ligneous species peaked at the range of 0.1 to 0.2 then decreased

Table 2 Classification of NBS-LRRs in genomes of five Rosaceae fruit species

\begin{tabular}{|c|c|c|c|c|c|}
\hline & F. vesca & M. domestica & P. bretschneideri & P. persica & P. mume \\
\hline Number of single gene & 97 & 232 & 172 & 121 & 182 \\
\hline Number of multi-gene & 47 & 516 & 297 & 233 & 170 \\
\hline Number of gene family & 12 & 107 & 86 & 53 & 49 \\
\hline Average members per family & 3.92 & 4.82 & 3.45 & 4.40 & 3.47 \\
\hline Proportion of multi-gene & $32.64 \%$ & $68.98 \%$ & $63.33 \%$ & $65.82 \%$ & $48.30 \%$ \\
\hline Number of TNL multi-gene & 9 & 147 & 137 & 95 & 82 \\
\hline Number of TNL gene family & 1 & 30 & 43 & 19 & 23 \\
\hline Proportion of TNL multi-gene & $39.13 \%$ & $67.12 \%$ & $61.99 \%$ & $74.22 \%$ & $53.59 \%$ \\
\hline Number of non-TNL multi-gene & 38 & 369 & 160 & 138 & 88 \\
\hline Number of non-TNL gene family & 11 & 77 & 43 & 34 & 26 \\
\hline Proportion of non-TNL multi-gene & $31.40 \%$ & $69.75 \%$ & $64.52 \%$ & $61.06 \%$ & $44.22 \%$ \\
\hline
\end{tabular}



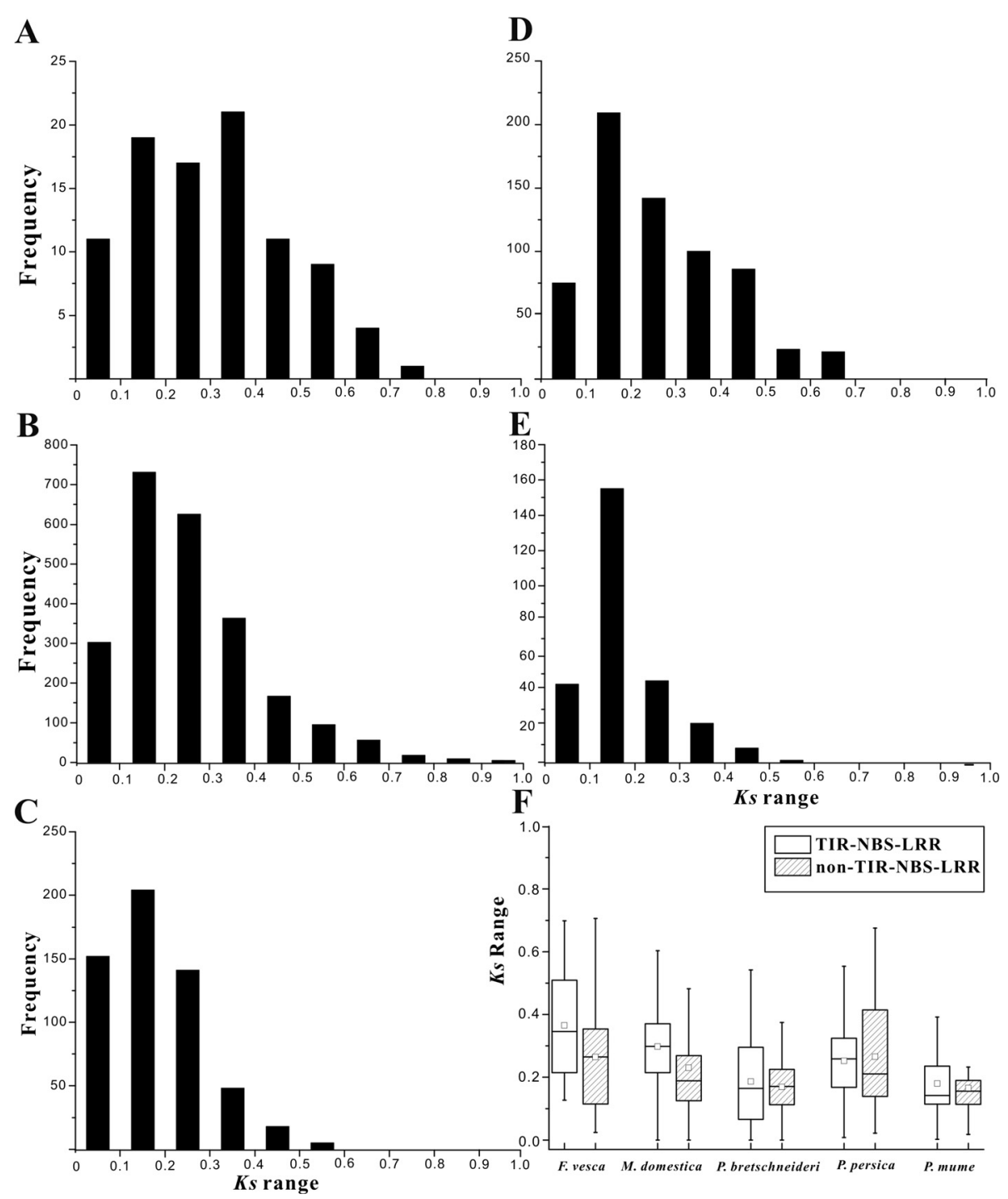

Figure 1 The $K s$ values of NBS-LRRs in five Rosaceae fruit species. A-E: the distribution of Ks frequency in the genomes of strawberry, apple, pear, peach and mei, respectively; $\mathbf{F}$ : The Ks ranges of TNLs and non-TNLs in the five species. The bars at the top and bottom of the whiskers mean maximum and minimum values; the top and bottom of the box represent third and first quartiles; the square and bar in the box mean average and median values.

slowly from 0.2 to 0.8 , indicating the relatively recent duplication of NBS-LRR genes in those species.

Figure $1 \mathrm{~F}$ shows the different distribution patterns of the $K s$ values exhibited between TNLs and non-TNLs in each species. The TNLs had broader distributions of $K s$ than non-TNLs in the genomes of apple, pear and mei, indicating that TNLs had longer duplication process than non-TNLs in these three species. The larger median and quartile ranges suggests that the $K s$ values of TNLs were significantly greater than those of non-TNLs (Mann-Whitney $U$ test) in strawberry $(P<0.01)$ and apple $(P<0.01)$, demonstrating that the corresponding TNL genes underwent duplication at different times in the two species.

\section{Phylogenetic analysis of NBS-LRR genes}

To further understand the duplication patterns of NBSLRR genes in the five genomes, an unrooted phylogenetic tree was constructed based on the nucleotide sequences of the core NBS domain by FastTree 2 (Figure 2). The phylogenetic tree showed few Rosaceaewide large duplication clusters despite the close evolutionary relationship between taxa, and the topology of genes was consistent with the relationship of species (Figure 2).

When the ML tree was divided into clades according to the bootstrap values $(>50)$, two types of clades which resulted from species-specific duplication (Figure 2: vertical light green lines) and lineage-specific duplication 


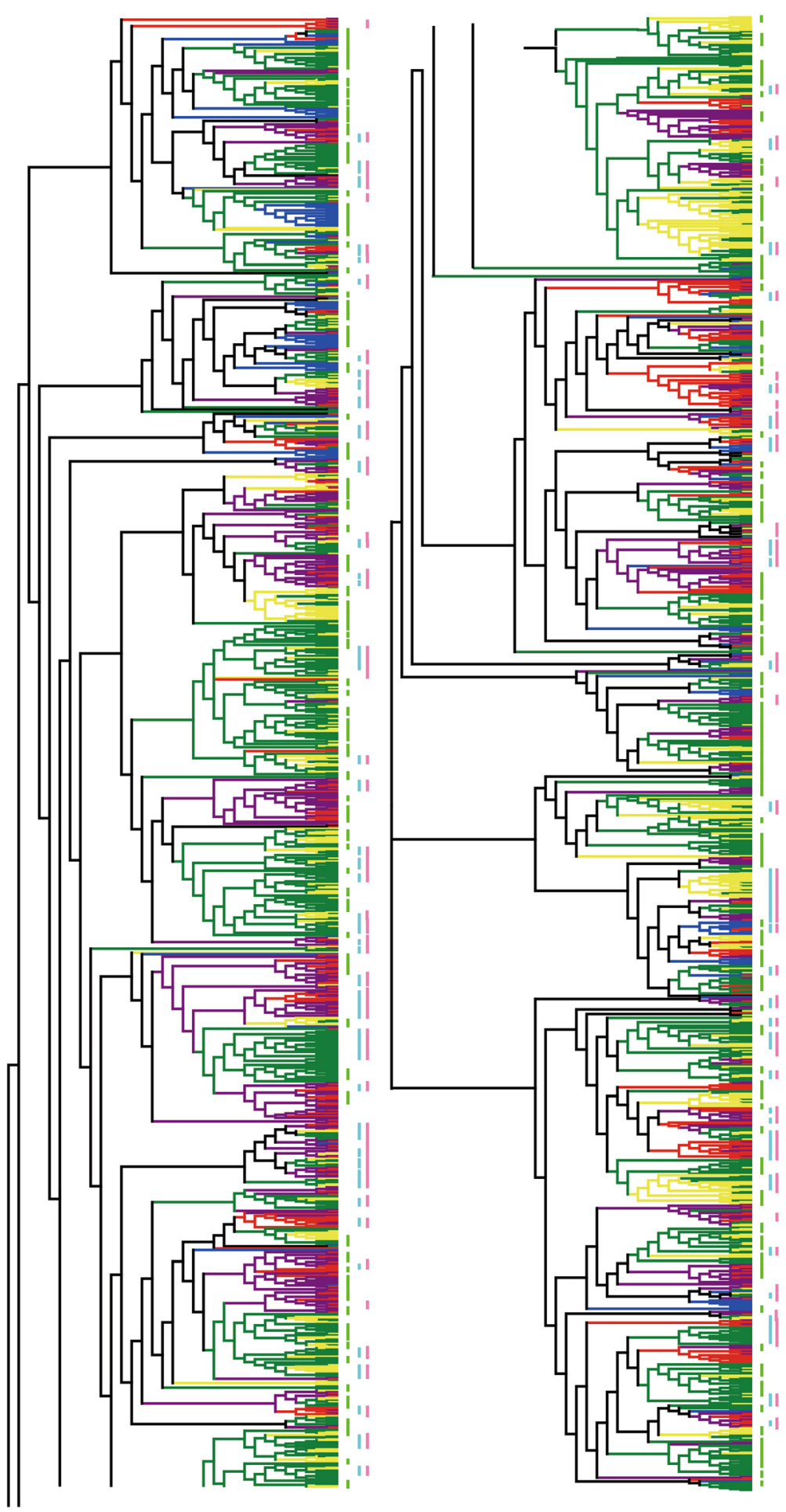

Figure 2 Phylogenetic tree of NBS-LRRs in the genomes of five Rosaceae fruit species. The blue, green, yellow, red and purple branches represent genes from strawberry, apple, pear, peach and mei, respectively; pink and sky blue line indicate lineage-specific duplication and species-specific duplication events in it, respectively; light green line means species-specific duplication. The tree was artificially divided into two parts because of space limitation. 
(Figure 2: vertical pink lines) could be clearly observed. The former were denoted as gene duplications of NBSLRR only occurring in one species, while the latter were composed of gene duplications in more than one species (Figure 2). Within the lineage-specific expansions, many species-specific duplication events (vertical sky blue lines) could also be found. There were 233 species-specific duplication clades and 152 lineage-specific duplication clades with 1083 species-specific duplicated NBS-LRR genes, which further indicated that duplication was the main contributor to the large amount of NBS-LRR genes in each of the five Rosaceae species. There were 650 genes in species-specific duplication clades (vertical light green lines) and 433 genes in species-specific duplication events in lineage-specific duplication clades, demonstrating that $52.39 \%(1083 / 2067)$ of the total NBS-LRR genes were involved in species-specific duplication in the five Rosaceae species. Among these genes, $89(98 / 144=$ $61.81 \%), 494(494 / 748=66.04 \%), 228(228 / 469=48.61 \%)$, $131(131 / 354=37.01 \%)$, and $141(141 / 352=40.05 \%)$ speciesspecies duplication genes were detected in strawberry, apple, pear, peach and mei, respectively. Although NBSLRR genes in strawberry appeared in only some parts of the phylogenetic tree, a relatively higher proportion of species-specific duplicated genes were found in strawberry genome. In addition, the relatively smaller percentages of species-specific duplication genes in peach and mei still showed that nearly $40 \%$ of the NBS-LRRs were generated after the split of the two closely-related Prunus species, whilst the remaining NBS-LRRs were directly obtained from the Prunus ancestor (Figure 2). Thus, our results indicate that species-specific duplication was the main factor driving NBS-LRR expansion in the five Rosaceae species.

To learn more about the evolutionary relationships between known $R$-genes encoding NBS-LRR proteins, we located them on the phylogenetic tree by BLAST search against whole genome CDSs of apple. Interestingly, the NBS-LRRs resistance to apple scab (Rvil5 and Rvil) and fire blight $\left(F B_{-} M R 5\right)$ were located in apple-specific or apple/pear-specific duplicate clades (data not shown). The Rvi5 gene had the highest identify with MDP0000754718, which clustered with MDP0000505414 and MDP0000 565527, which together formed a specific-specific duplicate clade of apple. For Rvi1, it had highest identity with MDP0000278168, which was located in a lineage-specific duplication clade composed of genes only present in apple and pear, whilst another gene encoding CC-NBS-LRR protein, FB_MR5, resided in an apple-specific duplicate clade.

\section{Nonsynonymous and synonymous substitution of NBS- LRR genes}

The ratio of nonsynonymous to synonymous nucleotide substitution $(\mathrm{Ka} / \mathrm{Ks})$ is used as an important indicator of selective constraint in gene diversification. A $K a / K s$ ratio greater than 1 indicates that genes are driven by positive selection, and a ratio of 1 indicates neutral selection, whereas the ratio less than 1 implies purifying selection. To identify the selective pressures working on NBS-LRR genes in the five Rosaceae genomes, $\mathrm{Ka} / \mathrm{Ks}$ ratios were estimated in each gene family by MEGA v5.0 [35].

Figure 3 shows that the majority of the NBS-LRR gene pairs (95.49\%) had $K a / K s$ ratios less than 1, including TNLs and non-TNLs, which indicated that most of the genes were driven by purifying selection in the five species. Nevertheless, 3 (0 vs. 3), 100 (32 vs. 68), 35 (13 vs. 22), 23 (9 vs. 14) and 17 (15 vs. 2) gene pairs had Ka/Ks ratios greater than 1 for TNLs $v$ s. non-TNLs in strawberry, apple, pear, peach and mei, respectively, demonstrating that some of NBS-LRR genes were under positive selection or relaxed selection for gene pairs with $\mathrm{Ka} / \mathrm{Ks}$ approximately equal to 1 . Among all gene pairs, 0 (0 vs. 0), 34 (7 vs. 27), 8 (4 vs. 4$), 7$ (5 vs. 2) and 6 (6 vs. $0)$ pairs had $\mathrm{Ka} / \mathrm{Ks}$ ratio approximately equal to 1 for TNLs vs. non-TNLs in strawberry, apple, pear, peach and mei, respectively, indicating that these genes might have undergone mutations causing nonfunctionalization or pseudogenization. The distribution ranges of $\mathrm{Ka} / \mathrm{Ks}$ ratios between non-TNLs were broader than those between TNLs according to the lengths of the boxes and whiskers in strawberry, apple and pear (Figure 3). Conversely, $\mathrm{Ka} / \mathrm{Ks}$ had narrower distribution between non-TNL genes than TNL genes in the two Prunus species (Figure 3). In spite of the differences in distribution ranges, TNLs had larger median and quartile values than non-TNLs in all five species. Except for the values in strawberry, the other $K a / K s$ ratios of TNLs and non-TNLs showed highly significant differences (Mann-Whitney $U$ test, $P<0.01$ ) in apple, pear, peach and mei. Interestingly, all TNLs had significant higher $\mathrm{Ka} / \mathrm{Ks}$ ratios than non-TNLs, suggesting that TNLs

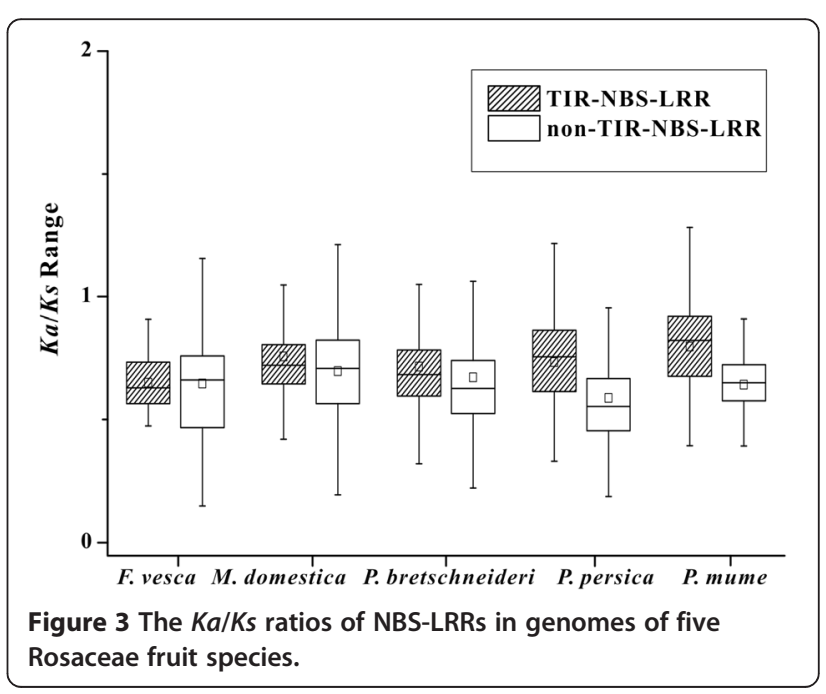


evolve faster and are under stronger selective pressures than non-TNLs.

\section{Selective pressures of NBS-LRRs among five Rosaceae species}

To further detect the evolutionary fate of NBS-LRR duplicates among the five Rosaceae species, site and branch models were implemented using PAML4 (phylogenetic analysis by maximum likelihood) [36] (Tables 3 and 4). Using the site model test, 168 gene families were estimated which contained three or more members, including 59 TNL gene families (strawberry: 1, apple: 14 , pear: 20 , peach: 12 and mei: 12) and 109 non-TNL gene families (strawberry: 7, apple: 41 , pear: 24, peach: 21 and mei: 16). The $2 \Delta \ln$ values supported the phenomenon that there were amino acid sites driven by positive selection in both TNL and non-TNL gene families (Tables 3 and 4). In TNL families, all duplicates examined by LR tests showed that the amino acid sites among them were under highly significant positive selection, except family6 in pear.

Table 3 Selective pressures of TNLs among five Rosaceae species

\begin{tabular}{|c|c|c|c|c|c|c|c|}
\hline Family no. & $K a / K s^{a}$ & $\omega^{\mathbf{b}}$ & $2 \Delta \ln$ & Family no. & $K a / K s^{a}$ & $\omega^{\mathbf{b}}$ & $2 \Delta \ln$ \\
\hline F. vesca & & & & P. bretschn & & & \\
\hline 0 & 0.65 & 0.64 & $178.25^{* *}$ & 28 & 0.69 & 0.65 & $127.83^{* *}$ \\
\hline M. domestica & & & & 29 & 0.49 & 0.55 & $26.94^{* *}$ \\
\hline 0 & 0.71 & 0.72 & $130.72^{* *}$ & 32 & 0.74 & 0.82 & $86.53^{* *}$ \\
\hline 1 & 0.78 & 0.80 & $169.72^{* *}$ & 37 & 0.88 & 0.92 & $34.57^{* *}$ \\
\hline 3 & 0.61 & 0.64 & $77.86^{* *}$ & 39 & 0.73 & 0.55 & $70.55^{* *}$ \\
\hline 4 & 0.70 & 0.70 & $34.50^{* *}$ & P. persica & & & \\
\hline 7 & 0.70 & 0.79 & $39.21^{* *}$ & 1 & 0.61 & 0.58 & $46.66^{* *}$ \\
\hline 9 & 0.88 & 1.15 & $269.70^{* *}$ & 2 & 0.78 & 0.69 & $200.14^{* *}$ \\
\hline 10 & 0.71 & 0.65 & $127.61^{* *}$ & 3 & 0.54 & 0.53 & $87.14^{* *}$ \\
\hline 13 & 0.53 & 0.65 & $151.63^{* *}$ & 5 & 0.51 & 0.47 & $22.47^{* *}$ \\
\hline 14 & 0.88 & 0.67 & $275.29^{* *}$ & 6 & 0.56 & 0.54 & $12.24^{* *}$ \\
\hline 15 & 0.77 & 0.68 & $263.14^{* *}$ & 7 & 0.87 & 0.95 & $404.73^{* *}$ \\
\hline 16 & 0.78 & 0.87 & $289.13^{* *}$ & 8 & 0.87 & 0.82 & $173.19^{* *}$ \\
\hline 23 & 0.97 & 1.06 & $177.42^{* *}$ & 9 & 0.81 & 0.81 & $132.38^{* *}$ \\
\hline 24 & 0.60 & 0.61 & $27.06^{* *}$ & 11 & 0.66 & 0.59 & $186.11^{* *}$ \\
\hline 25 & 0.74 & 0.70 & $155.33^{* *}$ & 12 & 0.83 & 0.65 & $92.60^{* *}$ \\
\hline P. bretschneideri & & & & 14 & 0.78 & 0.73 & $60.48^{* *}$ \\
\hline 2 & 0.54 & 0.57 & $292.28^{* *}$ & 16 & 0.84 & 0.82 & $49.62^{* *}$ \\
\hline 3 & 0.69 & 0.75 & $169.17^{* *}$ & P. mume & & & \\
\hline 4 & 0.65 & 0.76 & $143.59^{* *}$ & 0 & 1.15 & 1.31 & $257.80^{* *}$ \\
\hline 6 & 0.72 & 0.74 & $6.79^{*}$ & 2 & 0.89 & 1.03 & $333.07^{* *}$ \\
\hline 7 & 0.80 & 0.86 & $108.95^{* *}$ & 4 & 0.52 & 0.58 & $18.40^{* *}$ \\
\hline 10 & 0.65 & 0.69 & $127.79^{* *}$ & 6 & 0.80 & 0.81 & $173.58^{* *}$ \\
\hline 11 & 0.88 & 0.93 & $161.28^{* *}$ & 8 & 0.97 & 1.02 & $125.15^{* *}$ \\
\hline 14 & 0.65 & 0.67 & $125.28^{* *}$ & 10 & 0.60 & 0.51 & $30.89^{* *}$ \\
\hline 16 & 0.92 & 0.92 & $259.19^{* *}$ & 11 & 0.56 & 0.54 & $132.21^{* *}$ \\
\hline 17 & 0.78 & 0.88 & $35.67^{* *}$ & 12 & 0.89 & 0.94 & $344.19^{* *}$ \\
\hline 19 & 0.86 & 0.99 & $142.46^{* *}$ & 14 & 0.92 & 0.94 & $313.67^{* *}$ \\
\hline 21 & 1.08 & 1.25 & $130.03^{* *}$ & 16 & 0.75 & 0.71 & $99.29^{* *}$ \\
\hline 22 & 0.69 & 0.65 & $196.90^{* *}$ & 19 & 0.79 & 0.77 & $49.99^{* *}$ \\
\hline 25 & 0.56 & 0.47 & $51.69^{* *}$ & 20 & 0.89 & 0.92 & $127.40^{* *}$ \\
\hline 26 & 0.64 & 0.60 & $62.54^{* *}$ & & & & \\
\hline
\end{tabular}

${ }^{a}$ Average $K a / K s$ ratio of each gene family calculated by MEGA; ${ }^{b} d N / d S$ ratio for each gene family using branch model; $2 \Delta \ln$ represents the result of $L R$ test for site model; $^{*}$ and ${ }^{* *}$ represent significant $(2 \Delta \ln >5.991, p<0.05)$ and highly significant $(2 \Delta \ln >9.210, p<0.01)$ tests for positive selection between model M7 and M8. 
Table 4 Selective pressures of non-TNLs among five Rosaceae species

\begin{tabular}{|c|c|c|c|c|c|c|c|}
\hline Family no. & $K a / K s^{a}$ & $\omega^{\mathbf{b}}$ & $2 \Delta \ln$ & Family no. & $K a / K s^{a}$ & $\omega^{\mathbf{b}}$ & $2 \Delta \ln$ \\
\hline F. vesca & & & & P. bretschne & & & \\
\hline 0 & 1.01 & 1.37 & $244.51^{* *}$ & 12 & 1.13 & 1.14 & $174.51^{* *}$ \\
\hline 2 & 0.51 & 0.51 & $30.00^{* *}$ & 13 & 0.67 & 0.64 & $309.43^{* *}$ \\
\hline 3 & 0.72 & 0.78 & $163.67^{* *}$ & 17 & 0.69 & 0.72 & $270.23^{* *}$ \\
\hline 4 & 0.52 & 0.52 & $26.42^{* *}$ & 19 & 0.61 & 0.71 & $140.67^{* *}$ \\
\hline 5 & 0.35 & 0.39 & 3.41 & 21 & 0.71 & 0.88 & $173.72^{* *}$ \\
\hline 9 & 0.57 & 0.57 & $64.46^{* *}$ & 23 & 0.62 & 0.62 & $69.89^{* *}$ \\
\hline 10 & 0.52 & 0.53 & $30.72^{* *}$ & 24 & 0.96 & 0.96 & $101.27^{* *}$ \\
\hline M. domestica & & & & 25 & 0.66 & 0.67 & $75.95^{* *}$ \\
\hline 0 & 0.34 & 0.37 & $20.55^{* *}$ & 26 & 0.51 & 0.65 & $30.17^{* *}$ \\
\hline 2 & 0.75 & 0.65 & $34.70^{* *}$ & 27 & 1.70 & 0.68 & $38.52^{* *}$ \\
\hline 3 & 0.78 & 0.71 & $164.45^{* *}$ & 28 & 0.60 & 0.67 & $174.99^{* *}$ \\
\hline 6 & 0.55 & 0.58 & $47.64^{* *}$ & 29 & 1.21 & 1.19 & $124.18^{* *}$ \\
\hline 8 & 0.75 & 1.38 & $330.32^{* *}$ & 32 & 0.62 & 0.64 & $40.06^{* *}$ \\
\hline 9 & 0.40 & 0.46 & $11.37^{* *}$ & 33 & 0.35 & 0.40 & $63.30^{* *}$ \\
\hline 11 & 0.64 & 0.64 & $26.32^{* *}$ & 38 & 0.73 & 0.75 & $426.85^{* *}$ \\
\hline 13 & 0.55 & 0.58 & 3.41 & 40 & 0.20 & 0.28 & 1.27 \\
\hline 14 & 0.88 & 0.79 & $53.12^{* *}$ & 42 & 0.43 & 0.50 & $49.36^{* *}$ \\
\hline 15 & 0.87 & 0.45 & $157.04^{* *}$ & P. persica & & & \\
\hline 16 & 0.54 & 0.58 & $128.15^{* *}$ & 0 & 0.67 & 0.72 & $90.19^{* *}$ \\
\hline 17 & 0.65 & 0.59 & $45.42^{* *}$ & 1 & 0.48 & 0.46 & $94.92^{* *}$ \\
\hline 20 & 1.10 & 1.08 & $90.23^{* *}$ & 2 & 0.58 & 0.59 & $64.94^{* *}$ \\
\hline 22 & 1.02 & 1.33 & $48.89^{* *}$ & 3 & 0.51 & 0.57 & $81.35^{* *}$ \\
\hline 23 & 0.59 & 0.61 & $123.77^{* *}$ & 4 & 0.73 & 0.85 & $81.38^{* *}$ \\
\hline 24 & 0.53 & 0.65 & $17.75^{* *}$ & 5 & 0.56 & 0.60 & $53.61^{* *}$ \\
\hline 25 & 0.91 & 0.95 & $242.51^{* *}$ & 7 & 0.87 & 0.77 & $131.61^{* *}$ \\
\hline 27 & 0.55 & 0.62 & $236.80^{* *}$ & 10 & 0.54 & 0.56 & $39.07^{* *}$ \\
\hline 29 & 0.70 & 0.84 & $46.93^{* *}$ & 11 & 1.01 & 1.12 & $35.54^{* *}$ \\
\hline 30 & 0.54 & 0.59 & 5.43 & 12 & 0.53 & 0.51 & $161.31^{* *}$ \\
\hline 32 & 0.41 & 0.49 & 3.81 & 13 & 0.33 & 0.38 & 0.18 \\
\hline 35 & 0.89 & 0.62 & $141.09^{* *}$ & 14 & 0.59 & 0.59 & $68.99^{* *}$ \\
\hline 36 & 0.60 & 0.70 & $61.85^{* *}$ & 15 & 0.62 & 0.77 & $11.16^{* *}$ \\
\hline 37 & 0.65 & 0.71 & $30.67^{* *}$ & 16 & 0.72 & 0.87 & $149.36^{* *}$ \\
\hline 39 & 0.85 & 0.95 & $182.68^{* *}$ & 17 & 0.64 & 0.64 & $94.83^{* *}$ \\
\hline 41 & 0.67 & 0.70 & $133.44^{* *}$ & 20 & 0.48 & 0.53 & $28.45^{* *}$ \\
\hline 43 & 0.93 & 0.86 & $158.52^{* *}$ & 22 & 0.37 & 0.39 & 1.92 \\
\hline 46 & 0.76 & 0.76 & $88.84^{* *}$ & 23 & 0.53 & 0.61 & $17.38^{* *}$ \\
\hline 48 & 0.31 & 0.47 & 2.97 & 24 & 0.48 & 0.48 & $57.74^{* *}$ \\
\hline 49 & 0.70 & 0.91 & $18.54^{* *}$ & 29 & 0.62 & 0.62 & $156.86^{* *}$ \\
\hline 51 & 0.73 & 0.86 & $118.63^{* *}$ & 30 & 0.68 & 0.69 & $86.74^{* *}$ \\
\hline 52 & 0.84 & 0.86 & $88.35^{* *}$ & P. mume & & & \\
\hline 53 & 0.25 & 0.32 & 1.41 & 0 & 0.66 & 0.74 & $26.03^{* *}$ \\
\hline 54 & - & 0.00 & 0 & 2 & 0.73 & 0.72 & $118.53^{* *}$ \\
\hline
\end{tabular}


Table 4 Selective pressures of non-TNLs among five Rosaceae species (Continued)

\begin{tabular}{|c|c|c|c|c|c|c|c|}
\hline$\overline{56}$ & 0.91 & 1.04 & $100.03^{* *}$ & 3 & 0.68 & 0.73 & $173.81^{* *}$ \\
\hline 57 & 0.81 & 0.91 & $230.38^{* *}$ & 5 & 0.68 & 0.73 & $214.41^{* *}$ \\
\hline 59 & 0.74 & 0.70 & $278.72^{* *}$ & 6 & 0.67 & 0.70 & $49.62^{* *}$ \\
\hline 60 & 0.74 & 0.66 & $273.76^{* *}$ & 8 & 0.70 & 0.69 & $101.58^{* *}$ \\
\hline 70 & 0.82 & 0.78 & $208.35^{* *}$ & 10 & 0.64 & 0.62 & $97.65^{* *}$ \\
\hline 72 & 0.40 & 0.34 & $61.52^{* *}$ & 12 & 0.59 & 0.65 & $103.39^{* *}$ \\
\hline 75 & 0.73 & 0.55 & $47.28^{* *}$ & 14 & 0.63 & 0.69 & $63.55^{* *}$ \\
\hline \multicolumn{4}{|c|}{ P. bretschneideri } & 15 & 0.50 & 0.48 & $59.19^{* *}$ \\
\hline 0 & 0.60 & 0.67 & $312.45^{* *}$ & 17 & 0.82 & 0.79 & $156.79^{* *}$ \\
\hline 1 & 0.40 & 0.47 & $61.89^{* *}$ & 18 & 0.58 & 0.70 & $179.70^{* *}$ \\
\hline 2 & 0.70 & 0.78 & $113.38^{* *}$ & 19 & 0.43 & 0.49 & 3.83 \\
\hline 4 & 0.42 & 0.53 & $18.57^{* *}$ & 21 & 0.31 & 0.34 & $-2.00 \mathrm{E}-06$ \\
\hline 7 & 0.55 & 0.63 & $16.11^{* *}$ & 24 & 0.92 & 1.21 & $38.51^{* *}$ \\
\hline 9 & 0.54 & 0.61 & $54.18^{* *}$ & 25 & 0.78 & 0.89 & $15.13^{* *}$ \\
\hline 11 & 0.74 & 0.88 & $58.97^{* *}$ & & & & \\
\hline
\end{tabular}

${ }^{a}$ Average $\mathrm{Ka} / \mathrm{Ks}$ ratio of each gene family calculated by MEGA; ${ }^{\mathrm{b}} d N / d S$ ratio for each gene family using branch model; $2 \Delta \mathrm{ln}$ represents the result of LR test for site model; ${ }^{* *}$ represent highly significant $(2 \Delta \ln >9.210, p<0.01)$ tests for positive selection between model M7 and M8.

Similarly, in non-TNL gene families, LR tests showed that $88.99 \%$ of them had sites driven by highly significant positive selection. It was suggested that these positively selected sites provided relative high substitutions compared with others among NBS-LRR genes.

For $\omega$ values $>1$, a higher substitution rate is characteristic of neofunctionalization between duplicates according to Ohno's model [37]; a $\omega$ value $\approx 1$ suggests a constant loss rate caused by neutral nonfunctionalization; and under subfunctionalization, the loss rate is steady at first, then declines leading to a $\omega$ value $<1$ [38]. Although most of the genes investigated had positively selected sites, they were still under purifying selection. In total $91.07 \%$ of all gene families had average $\omega$ ratios smaller than 1 and $7.14 \%$ of them were larger than 1 . Moreover, there were still some gene families had $\omega$ approximately equal to 1 , which indicated that they were nonfunctionalized duplicates. It was shown that most of NBS-LRR genes became subfunctionalized duplicates but with relative high substitution between sites among them, supporting the rapid subfunctionalization model followed by neofunctionalization [39].

Evolutionary analysis of RPW8 domain-containing NBS-LRRs In Arabidopsis, the RPW8 gene contains an RPW8 domain which confers broad resistance to powdery mildew [40]. In strawberry, apple, pear, peach and mei, 24, 20, 22, 11 and 13 NBS-LRR genes respectively, encoded not only NBS domain and LRR motif but also a RPW8 domain (PF05659.6). With the exception of two genes (MDP0000196734 \& Pb11_0_1_0), all of the 90 RPW8 domain-containing NBS-LRRs in all five species were
non-TNL genes, including $33 \mathrm{CC}-\mathrm{NBS}-\mathrm{LRR}$ genes and 55 X-NBS-LRR genes.

In the un-rooted phylogenetic tree constructed according to the nucleotide sequences of RPW8 domain-coding regions, ten groups were detected in the tree based on the topology (Figure 4). The RPW8 domain-containing NBSLRRs exhibited two distinct topologies: a group of genes clustered together with shorter branch lengths (Group 1 to $6)$, whereas another clustered with longer branch lengths and deeper nodes (Group 7 to 10), indicating that the latter might be the ancestral genes of the former. Interestingly, gene members in Group 6 exhibited relatively high identities compared to the RPW8 genes in Arabidopsis using BLAST search, indicating that these genes might be considered as $R$-gene candidates. To investigate the evolutionary pattern and selective constraints, nucleotide diversities and $K a / K s$ ratios for the genes in each group were calculated. Genes in Group 7 to 10 had highly significant nucleotide diversity compared with those in Group 1 to 6 (Additional file 2: Table S2, Mann-Whitney U test, $P<0.01)$ their longer branch lengths demonstrating that these genes showed two different evolutionary patterns. (Additional file 3: Table S3) shows that, with the exception of three gene pairs (MDP0000310183/MDP00001 80482, MDP0000310183/ MDP0000286425 and MDP00 00310183/ MDP0000214225), all of the gene pairs had $K a / K s$ ratios less than 1 , indicating that most of the RPW8 domain-containing NBS-LRRs were under purifying selection. Furthermore, the $K a / K s$ ratios of Group 1 to 6 were higher than those of Group 7 to 10 (0.42 vs. 0.37), which demonstrated that former were under stronger selective pressure than latter. 


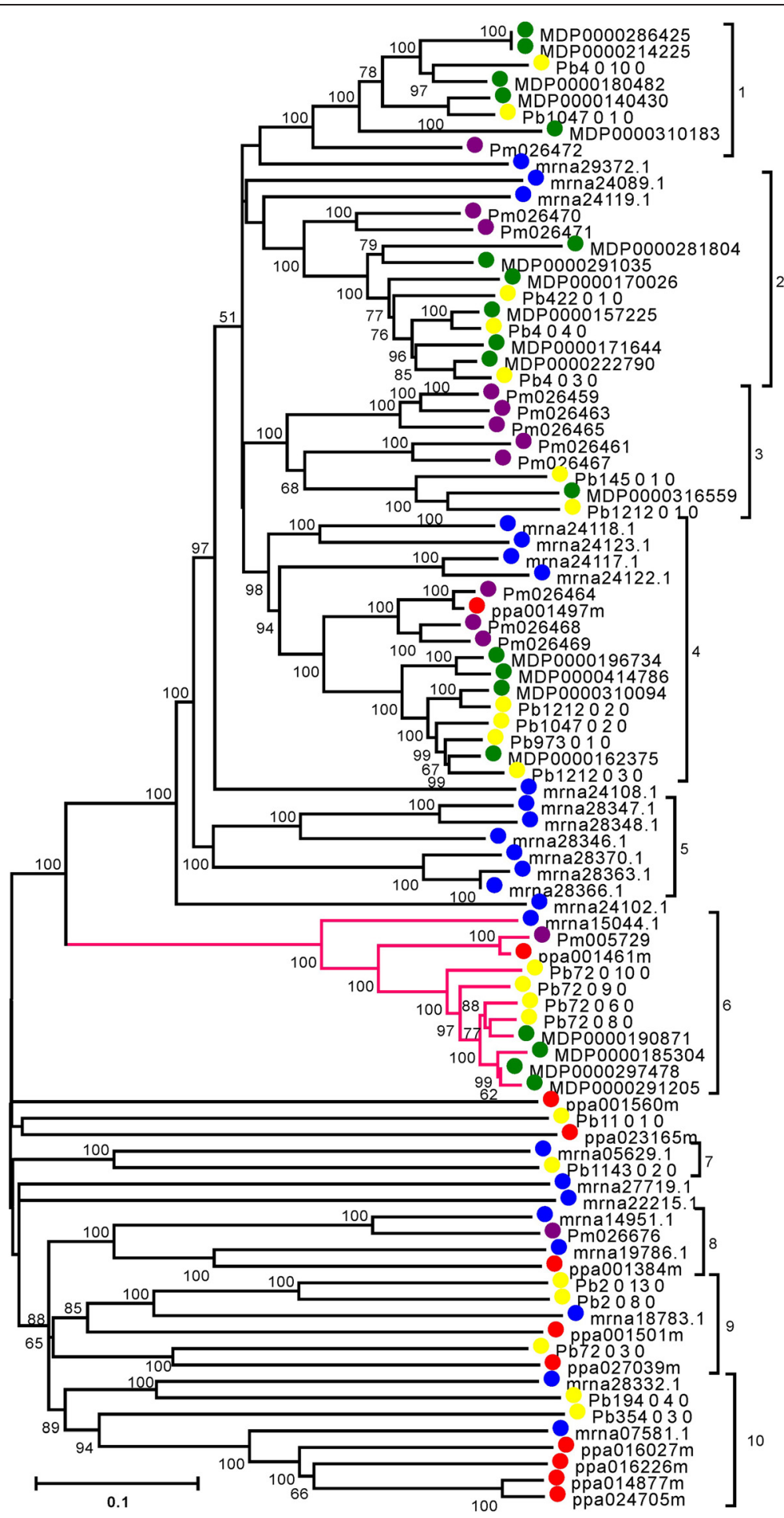

Figure 4 A phylogenetic tree of RPW8 domain-containing NBS-LRRs in the genomes of five Rosaceae fruit species. Blue dots: strawberry, green dots: apple, yellow dots: pear, red dots: peach, and purple dots: mei. Red branch represents Group 6 whose members have the highest identity with RPW8 gene. 


\section{Discussion}

\section{Recent duplication in NBS-LRR genes}

Gene duplication is one of the prevalent forces leading to increased gene numbers and genome complexity in eukaryotes [41-44]. Gene duplication contributes to the evolution of gene networks [45] and provides the raw material for the evolution of novel genetic systems [37] and gene function $[46,47]$.

NBS-LRR genes are one of the largest gene families in plant genomes and the largest class of known disease resistance genes ( $R$-genes), which play important roles in response to pathogens $[5,7,48,49]$. Absolute numbers of NBS-LRR genes varied between the four ligneous species investigated here, but similar relative proportions of NBS-LRR genes were identified as in A. thaliana [5]. The smaller number and proportion of NBS-LRR genes identified in strawberry ( $F$. vesca) might be associated with its smaller genome and its lack of genome-scale duplications that have been identified in other rosids [28]. Additionally, the relative proportions of NBS-LRRs in the four woody genomes analyzed here were similar with those found in the rice genome [7], despite the different absolute number of NBS-LRR genes. Therefore, the number of NBS-LRR proteins was not related to the whole-genome predicted protein numbers. The NBSLRR genes were mainly (approximately 50\%) generated by recent gene duplications in the five Rosaceae species, especially in the four woody species according to relatively strict criteria (coverage $>70 \%$ and identity $>70 \%$ ), and exceeding $50 \%$ of NBS-LRR genes were still detected in three woody species based on strict standards $(>80 \%)$, which were previously used as the proxy for the detection of recent duplication events $[7,8]$. The $K s$ distributions also support the hypothesis that recent duplication events resulted in the expansion of NBS-LRR genes in the five species, with the proportions of genes in the Ks range of 0 to 0.2 being $32.26 \%$ (strawberry), $43.57 \%$ (apple), 62.68\% (pear), 43.29\% (peach) and 72.10\% (mei). The $K s$ peak at the same narrow range $(0.1 \sim 0.2$, Figure 1) observed in the four woody species suggests that the corresponding duplications might have occurred at the same period considering these NBS-LRR genes derived from the common ancestor with the similar nucleotide mutation rates. In apple genome, $K s$ of all paralogs peaked around 0.2 for a recent whole genome duplication, which occurred 30-45 MYA [29]. Therefore, it could be inferred that the recent duplication ( $K s=0.1 \sim 0.2)$ of NBS-LRR genes might occurred less than 30-45 MYA.

In addition, duplicate genes most likely face three evolutionary fates: (a) nonfunctionalization or pseudogenization might cause one gene copy to lose function; (b) subfunctionalization partitions ancestral gene function in daughter copies; and (c) neofunctionalization leads to one copy retaining its original function and the other evolving a novel function [50,51]. In our study, it was found that most of NBS-LRR gene families (91.07\%) have undergone subfunctionalization $(\omega<1)$, whilst a small number have undergone nonfunctionalization $(\omega \approx 1)$ or neofunctionalization $(\omega>1)$. Although the nonfunctionalization model is thought to be the most common fate of duplicates, previous research supports the subfunctionalization model in the preservation of complex genes after duplication [52]. Among the NBSLRR genes under subfunctionalization, most of them had positively selected sites with relative high substitution rate, consistent with previous research that subfunctionalized duplicated genes act as a transition state to neofunctionalization, which is a prolonged and substantial process during evolution of gene duplication $[39,53]$.

\section{Species-specific duplication mainly contributes to NBS-LRR gene expansion}

Species-specific duplication is defined as the expansion of a gene family only in one species compared with other species. This phenomenon was observed in this investigation, with clustering of paralogous genes together with each other but not with orthologous genes in phylogenetic trees (Figure 4). This result is in accord with the fact that NBS-LRR genes have been shown to undergo gene expansion after speciation, in species such as A. thaliana [5,54], O. sativa [48], Zea mays [8], Populus and $V$. vinifera [7]. In the 101 lineage-specific clades identified, 122 species-specific duplicate clades exhibited a "one-to-one" topology and 263 speciesspecific duplication events showed a "one-to-many" topology (Additional file 4: Figure S1). The "one-to-many" topology demonstrated that the gene copies inherited from ancestral species were retained in one species, but that they were reserved and expanded into multi-copies in another species after species divergence, in a similar way to what has been reported in four gramineous plants, $Z$. mays, S. bicolor, B. distachyon and O. sativa [8]. In addition, a relatively larger proportion of NBS-LRR genes were counted in strawberry (61.81\%), apple (66.04\%), pear (48.61\%), peach (37.01\%), and mei $(40.05 \%)$ in speciesspecific duplicates clades of ML tree. This suggests that species-specific duplication led to the major expansion of NBS-LRR genes in the five Rosaceae species studied here. In addition, the existence of lineage-specific or speciesspecific clades indicates the existence of mechanisms for cluster conservation, as reported by Plocik et al. [55].

Previous studies have shown that species-specific gene duplication leads to species-specific gene functions and features, which could improve the adaptation of the corresponding species to the changing environment [11,56-59]. Although the five species in this study belong to the same family, the different species have markedly 
different characteristics. The five plants could be divided into two classes, herbaceous and ligneous plants, and the NBS-LRR genes in the only herbaceous plant strawberry, exhibited a different evolutionary pattern and feature from those in the other four ligneous plants. For example, the least absolute number (144), relative proportion $(0.44 \%)$ and multi-gene proportion $(32.64 \%)$ of NBS-LRR genes were found in strawberry compared with other plants (Tables 1 and 2) and an even distribution of duplication time ( $K s$ value) was only detected (Figure 1) in strawberry. These data indicate that NBSLRR genes in strawberry experienced a gradual accumulating process to adapt to their specific physiological characteristics and ecological changes. One reason for the higher number of $R$-genes observed in the four woody species compared with strawberry may be that long-lived perennial woody plants face more abiotic or biotic stresses before reproduction [60] or fruit ripening [61]. Therefore, the larger $R$-gene numbers and proportions in four woody species could be considered as disease resistance gene pools to rapidly evolve novel resistance specificities [62]. Furthermore, NBS-LRR genes of the four ligneous plants also show some distinct features from each other, such as the different topologies of NBS-LRRs and species-specific duplicate clades in each genome (Figure 2).

Locating known Rosacous resistance genes, and specifically those of apple in the tree showed that the two apple scab genes (Rvi1 and Rvi5) clustered in two clades specific for apple and pear, and the same result was observed for the CC-NBS-LRR gene of Malus $\times$ robusta 5 confering the resistance to fire blight (data not shown). These data suggest that different Rosaceae plants have different environment and life histories, thus speciesspecific $R$-genes are duplicated to response to their specific ecological environment, pathogens or natural selective pressures.

Several clades include a mixture of NBS-LRR genes from Fragaria, Malus, Pyrus, and Prunus, indicating that similar resistance genes are still shared in different genera of the Rosaceae, which support the monophyletic origin of the four genera. Most of these clades are composed of CNL genes whilst a few contain TNL genes. Moreover, similar resistance gene analogues (RGAs) were shared in Malus, Pyrus, and Prunus, indicating high conservation of specific RGAs and suggesting a monophyletic origin of these genera as well [63].

\section{Different evolutionary patterns between TNL and non-TNL genes}

NBS-LRR genes with ancient origins can be divided into two types, TNLs and non-TNLs, both of which can be found in gymnosperms and angiosperms [64]. Interestingly, TNLs are present in eudicots, but absent in monocots $[65,66]$. The data presented here, along with previous studies suggests that TNL and non-TNL genes exhibit different evolutionary patterns $[6,11]$. In the $A$. thaliana and A. lyrata genomes, the branch lengths of TNL genes clades were significantly longer than those of non-TNLs in the phylogenetic tree, indicating that TNL genes might evolve faster than non-TNLs [6]. In this study, the estimation of synonymous and nonsynonymous rates permitted detection of the evolutionary patterns between TNL and non-TNL duplicate genes. The significantly greater $K s$ values of TNLs than those of non-TNLs in strawberry and apple genomes (MannWhitney $\mathrm{U}$ test, $P<0.01$ ) demonstrate that TNL duplicated earlier and had a faster evolutionary rate compared with non-TNL duplicates within the two species, respectively. In addition, the similar tests and phenomenon were also reported in the soybean genome (1.6-fold, $P<0.001)$ [11] and Arabidopsis relative genomes (1.4-fold, $P<0.05$ ) [6]. Thus, this suggests that TNLs and non-TNLs have different evolutionary rates in responding to coevolving pathogens.

$\mathrm{Ka} / \mathrm{Ks}$ ratios were estimated to detect the diversifying selection pressures on TNL and non-TNL genes. TNLs had more $\mathrm{Ka} / \mathrm{Ks}$ ratios greater than 1 compared with non-TNLs. TNLs had significantly greater $K a / K s$ ratios than non-TNLs, consistent with the results detected in soybean genome, suggesting that stronger selective pressure might act on TNLs than on non-TNLs. The rapid evolutionary pattern of TNL genes might be one the strategies used by plants to protect themselves against diverse pathogens. However, in poplar and grapevine, non-TIR NBS families had significantly greater $\mathrm{Ka} / \mathrm{Ks}$ ratios than TIR NBS families $(P<0.05)[7,67]$. These results suggested that different plants with different life histories, thus the diverse evolution of TNLs and nonTNLs, might be driven by specific ecological environments. Moreover, independent evolution of the TNLs and non-TNLs could be detected in the phylogenetic trees of NBS-LRRs from each species (Additional files 4, 5, 6, 7 and 8: Figure S1-S5), demonstrating that the five trees were all divided into two parts: TNLs and nonTNLs, except some XNLs or CNLs located in TNL clades, which was previously suggested in the $V$. vinifera genome [68]. Therefore, TNL genes and non-TNL genes most likely have different evolutionary patterns to adapt to different pathogens.

An interesting domain structure, RPW8-NBS-LRR, was found in 88 non-TNLs among the NBS-LRR genes in the five Rosaceae species studied, including $33 \mathrm{CNL}$ and $55 \mathrm{XNL}$ genes. We infer from this that the novel domain structure might have occurred from the fusion of an RPW8 domain with a CNL [7] or XNL. Furthermore, the similar architecture was also detected in grapevine and poplar, involving five CNLs and one XNL, 
respectively [7], far fewer than the corresponding gene numbers detected in the five Rosaceae genomes in this investigation (24 in strawberry, 20 in apple, 22 in pear, 11 in peach and 13 in mei). The high number in the five species compared with grapevine and poplar might be a result of specific duplication events that have occurred in the evolutionary history of the Rosaceae to adapt to Rosaceae-specific pathogens. However, there were distinct gene numbers of RPW8-NBS-LRR between the five species, caused by species-specific duplication (Figure 4) to respond to their species-specific functional requirement [11,56-59]. The RPW8 domain is shared with the Arabidopsis RPW8 protein exhibiting broad resistance to powdery mildew [40], suggesting that the novel domain structure might provide distinctive function for plant defense system, such as higher powdery mildew resistance, especially the members in Group 6 (Figure 4), which might be the candidate gene for powdery mildew resistance.

In Rosaceae, most of woody perennial plants have a long intergeneration cycle and large plant sizes, which limits rapid breeding for disease resistance in these plants. The selective pressure of NBS-LRR genes in the five Rosaceae genomes demonstrated different selection pressures. Although most of paralogous pairs had $\mathrm{Ka} / \mathrm{Ks}$ ratios less than 1 , some paralogous pairs had $\mathrm{Ka} / \mathrm{Ks}$ ratios greater than 1 , indicating that these genes were driven by positive selection. The combination of the genetic relationships of NBS-LRR genes shown in the phylogenetic trees (Figures 2 and 4), the natural selective pressures on those genes and the $R$-genes identified in previous studies, will enable the effective selection of candidate genes for disease resistance breeding in Rosaceae crops.

\section{Conclusions}

Based on a genome-wide survey, we identified 144, 748, 469, 354 and 352 NBS-LRR genes in strawberry, apple, pear, peach and mei, respectively. We found that recent duplications $(<30$ - 45 MYA) generated the higher proportion of multi-genes and similar Ks peaks (0.1- 0.2) in NBS-LRRs of the four woody perennial Rosaceae species. In the phylogenetic tree, we detected species-specific duplication leading to high percentages of NBS-LRR genes in strawberry $(61.81 \%)$, apple (66.04\%), pear $(48.61 \%)$, peach $(37.01 \%)$ and mei (40.05\%), and suggest that species-specific duplication has mainly contributed to the expansion of NBS-LRR genes in the five Rosacese species. In addition, the $K s$ and $K a / K s$ values of TNLs were significantly greater than those of non-TNLs, indicating that TNLs evolved rapidly with different evolutionary patterns to response to distinct pathogens compared with non-TNLs, and most NBS-LRRs had $\mathrm{Ka} /$ $K s$ ratios less than 1 , demonstrating that they were driven by purifying selection and their evolutionary fates were towards subfunctionalization.

\section{Methods}

\section{Identification of NBS-LRR genes and classification of the} gene family

The whole genome sequences and annotations of woodland strawberry ( $F$. vesca) [28], apple ( $M . \times$ domestica) [29] and peach ( $P$. persica) [31] were downloaded from the FTP site of Phytozome v9.0 (ftp://ftp.jgi-psf.org/pub/ compgen/phytozome/v9.0). The pear (P. bretschneideri) [30] assembled sequences were retrieved from website of the Center for Pear Engineering Technology Research, Nanjing Agricultural University (http://peargenome.njau. edu.cn/), whilst the mei (P. mume) [32] genome sequences and annotations were obtained from Beijing Forestry University (http://prunusmumegenome.bjfu.edu.cn/).

The standard NB-ARC domain (PF00931) was first obtained from the Pfam website [69] (http://pfam.sanger. ac.uk/) as the query sequence to BLAST against the whole genome CDSs, and candidate CDSs were generated using TBLASTN searches with an expectation value $\leq 10^{-4}$ in strawberry, apple, peach and mei. The same standard NB-ARC domain was used in TBLASTN searches against assembled genome sequence scaffolds of pear genome using the same parameters. All BLAST hits together with 3,000 to $6,000 \mathrm{bp}$ of flanking sequence were manually annotated to produce complete CDSs using the program of FGENESH on Softberry website (http://linux1.softberry.com/berry.phtml).

Pfam analysis was then used to verify the presence of NB-ARC domain and LRR motif in all candidates identified. The SMART protein motif analysis (http://smart. embl-heidelberg.de/) was performed to improve the accuracy and integrity of LRR identification. Subsequently, the NBS-LRR genes were determined by using the combination results of Pfam and SMART analysis. Finally, all sequences were analysed to further verify the presence of TIR or CC domain using Pfam and COILS (http:// embnet.vital-it.ch/software/COILS_form.html) databases, which were used to classify the NBS-LRR genes into two sub-groups: TIR-NBS-LRR genes which contain TIR domain and non-TIR-NBS-LRR genes which contain CC or other (X) domains.

All-versus-all BLASTN searches were performed with an E-value of 1.0 across the NBS-LRR CDSs in the five Rosaceae species. Genes were divided into gene families based on (1) the cutoff of coverage larger than $70 \%$ (aligned sequence lengths/gene lengths), and (2) the identity between sequences exceeding $70 \%$.

\section{Sequence alignment and phylogenetic analysis}

The amino acid sequences of all NB-ARC domains were aligned using the MUSCLE program with default options 
in MEGA v5.0 [35]. Subsequently, a Maximum Likelihood (ML) method was used to construct the phylogenetic tree with Jukes-Cantor model of nucleotide evolution and 1,000 bootstraps through FastTree v2 [70]. For RPW8 domain-containing NBS-LRR genes, the alignments were obtained by the same method and used to construct the phylogenetic tree based on NJ method using pairwise deletion of gaps and kimura-2 model with 1,000 replicates in MEGA v5.0 [35].

\section{Estimation of nonsynonymous substitutions and synonymous substitutions}

The nucleotide sequences of CDSs in each gene family were aligned based on the protein sequences by using Clustalw 2.0 [71]. The nonsynonymous substitutions $(K a)$ and synonymous substitutions $(K s)$ and nonsynonymous to synonymous substitution ratios $(K a / K s)$ were estimated in each gene family according to the alignments in MEGA v5.0 [35].

\section{Test for selective pressures}

The PAML4 [36] package was used to perform the site model and branch model test to detected selective pressures of NBS-LRR genes among five Rosaceae species. For the site model, one single $d N / d S$ ratio (model $=0)$ and models M7 (beta) and M8 (beta- $\omega)$ (NS site $=78$ ) were applied among all gene families containing three or more members. The LR test between model M7 and M8 was also performed by using critical value of chi-square 5.991 $(p<0.05, d f=2)$ and $9.210(p<0.01, d f=2)$. One single $d N /$ $d S$ ratio (model $=0$ ) and models 0 (NS site $=0$ ) were implemented using the codeml program for branch models.

\section{Additional files}

Additional file 1: Table S1. Gene families of NBS-LRRs in the five Rosaceae fruit genomes.

Additional file 2: Table S2. Nucleotide diversity of RPW8 domain-containing genes in each group.

Additional file 3: Table S3. Ka/Ks ratios of RPW8 domain-containing genes in each group.

Additional file 4: Figure S1. Phylogenetic tree of NBS-LRR genes in strawberry genome. Fuchsia branches represent TNL genes and light blue branches represent non-TNL genes.

Additional file 5: Figure S2. Phylogenetic tree of NBS-LRR genes in apple genome. Fuchsia branches represent TNL genes and light blue branches represent non-TNL genes.

Additional file 6: Figure S3. Phylogenetic tree of NBS-LRR genes in pear genome. Fuchsia branches represent TNL genes and light blue branches represent non-TNL genes.

Additional file 7: Figure S4. Phylogenetic tree of NBS-LRR genes in peach genome. Fuchsia branches represent TNL genes and light blue branches represent non-TNL genes.

Additional file 8: Figure S5. Phylogenetic tree of NBS-LRR genes in mei genome. Fuchsia branches represent TNL genes and light blue branches represent non-TNL genes.

\section{Abbreviations}

NBS-LRR: Nucleotide binding sites-leucine-rich repeats; $R$ gene: Resistance gene; CDS: Nucleotide coding sequences.

\section{Competing interests}

The authors declare that they have no competing interests.

\section{Authors' contributions}

$Y Z$ and $Z M C$ designed and initiated this study. $Y Z$ and $H Y$ carried out the bioinformatic analyses. YZ wrote the manuscript. DJS, MM and ZMC critically revised the manuscript. All authors read and approved the final manuscript.

\section{Acknowledgments}

This study was supported by Ministry of Agriculture 948 project (2011-421).

\section{Author details}

${ }^{1}$ College of Horticulture, Nanjing Agricultural University, Nanjing 210095, China. ${ }^{2}$ Centre for Research and Innovation, Fondazione Edmund Mach, San Michele all'Adige 38010, Italy. ${ }^{3}$ Department of Plant Science, University of Tennessee, Knoxville 37996, USA.

Received: 15 April 2014 Revised: 5 August 2014

Accepted: 29 January 2015

Published online: 14 February 2015

\section{References}

1. Dangl JL, Jones JDG. Plant pathogens and integrated defence responses to infection. Nature. 2001:411(6839):826-33.

2. McHale L, Tan XP, Koehl P, Michelmore RW. Plant NBS-LRR proteins: adaptable guards. Genome Biol. 2006;7(4):212.

3. Ellis JG, Lawrence GJ, Luck JE, Dodds PN. Identification of regions in alleles of the flax rust resistance gene $L$ that determine differences in gene-for-gene specificity. Plant Cell. 1999;11(3):495-506.

4. Parker JE, Coleman MJ, Szabo V, Frost LN, Schmidt R, van der Biezen EA, et al. The Arabidopsis downy mildew resistance gene RPP5 shares similarity to the toll and interleukin-1 receptors with N and L6. Plant Cell. 1997;9(6):879-94

5. Meyers BC, Kozik A, Griego A, Kuang HH, Michelmore RW. Genome-wide analysis of NBS-LRR-encoding genes in Arabidopsis. Plant Cell. 2003;15 (4):809-34.

6. Chen $\mathrm{QH}$, Han ZX, Jiang HY, Tian DC, Yang SH. Strong Positive Selection Drives Rapid Diversification of R-Genes in Arabidopsis Relatives. J Mol Evol. 2010;70(2):137-48.

7. Yang SH, Zhang XH, Yue JX, Tian DC, Chen JQ. Recent duplications dominate NBS-encoding gene expansion in two woody species. Mol Genet Genomics. 2008;280(3):187-98.

8. Li J, Ding J, Zhang W, Zhang YL, Tang P, Chen JQ, et al. Unique evolutionary pattern of numbers of gramineous NBS-LRR genes. Mol Genet Genomics. 2010;283(5):427-38.

9. Ameline-Torregrosa C, Wang BB, O'Bleness MS, Deshpande S, Zhu H, Roe B, et al. Identification and characterization of nucleotide-binding site-leucine-rich repeat genes in the model plant Medicago truncatula. Plant Physiol. 2008;146(1):5-21.

10. Meyers BC, Kaushik S, Nandety RS. Evolving disease resistance genes. Curr Opin Plant Biol. 2005;8(2):129-34.

11. Zhang XH, Feng Y, Cheng H, Tian DC, Yang SH, Chen JQ. Relative evolutionary rates of NBS-encoding genes revealed by soybean segmental duplication. Mol Genet Genomics. 2011;285(1):79-90.

12. Longhi S, Giongo L, Buti M, Surbanovski N, Viola R, Velasco R, et al. Molecular genetics and genomics of the Rosoideae: state of the art and future perspectives. Horticulture Res. 2014; 1 .

13. Marchant R, Davey MR, Lucas JA, Lamb CJ, Dixon RA, Power JB. Expression of a chitinase transgene in rose (Rosa hybrida L.) reduces development of blackspot disease (Diplocarpon rosae Wolf). Mol Breed. 1998:4(3):187-94.

14. Zeller W. Resistance and Resistance Breeding in Ornamentals 1. EPPO Bull. 1979:9(1):35-44.

15. Amil-Ruiz F, Blanco-Portales R, Munoz-Blanco J, Caballero JL. The strawberry plant defense mechanism: a molecular review. Plant Cell Physiol. 2011;52(11):1873-903.

16. Shulaev V, Korban SS, Sosinski B, Abbott AG, Aldwinckle HS, Folta KM, et al. Multiple models for Rosaceae genomics. Plant Physiol. 2008;147(3):985-1003. 
17. Troggio M, Gleave A, Salvi S, Chagné D, Cestaro A, Kumar S, et al. Apple, from genome to breeding. Tree Genet Genomes. 2012;8(3):509-29.

18. Evans KM, James CM. Identification of SCAR markers linked to PI-w mildew resistance in apple. Theor Appl Genet. 2003;106(7):1178-83.

19. Durel C, Van de Weg E, Venisse J, Parisi L. Localisation of a major gene for apple scab resistance on the European genetic map of the Prima x Fiesta cross. IOBC wprs Bull. 2000;23(12):245-8.

20. Hemmat M, Brown SK, Weeden NF. Tagging and mapping scab resistance genes from R12740-7A apple. J Am Soc Hortic Sci. 2002;127(3):365-70.

21. Quarta R, Dettori MT, Sartori A, Verde I. Genetic linkage map and QTL analysis in peach. Acta Hortic. 2000;521:233-41.

22. Xu Q, Wen X, Deng X. Isolation of TIR and nonTIR NBS-LRR resistance gene analogues and identification of molecular markers linked to a powdery mildew resistance locus in chestnut rose (Rosa roxburghii Tratt). Theor Appl Genet. 2005;111(5):819-30.

23. Galli P, Patocchi A, Broggini GA, Gessler C. The Rvi15 (Vr2) apple scab resistance locus contains three TIR-NBS-LRR genes. Mol Plant Microbe Interact. 2010;23(5):608-17.

24. Cova V, Lasserre P, Velasco R, Malnoy M. High-resolution genetic map of the Rvi1 (Vg) apple scab resistance locus. In: Proceedings of the 54rd Italian Society of Agricultural Genetics Annual Congress-SIGA 2010: poster communication abstract 4.55.ISBN: 978-88-904570-0-5. handle:http:// hdl.handle.net/10449/18961.

25. Fahrentrapp J, Broggini GA, Kellerhals M, Peil A, Richter K, Zini E, et al. A candidate gene for fire blight resistance in Malus $\times$ robusta 5 is coding for a CC-NBS-LRR. Tree Genet Genomes. 2013;9(1):237-51.

26. Gardiner SE, Norelli JL, de Silva N, Fazio G, Peil A, Malnoy M, et al. Putative resistance gene markers associated with quantitative trait loci for fire blight resistance in Malus 'Robusta 5' accessions. BMC Genet. 2012;13:25.

27. Malnoy M, Martens S, Norelli JL, Barny MA, Sundin GW, Smits TH, et al. Fire blight: applied genomic insights of the pathogen and host. Annu Rev Phytopathol. 2012;50:475-94.

28. Shulaev V, Sargent DJ, Crowhurst RN, Mockler TC, Folkerts O, Delcher AL, et al. The genome of woodland strawberry (Fragaria vesca). Nat Genet. 2011;43(2):109-16.

29. Velasco R, Zharkikh A, Affourtit J, Dhingra A, Cestaro A, Kalyanaraman A, et al. The genome of the domesticated apple (Malus $x$ domestica Borkh.). Nat Genet. 2010:42(10):833 - +.

30. Wu J, Wang ZW, Shi ZB, Zhang S, Ming R, Zhu SL, et al. The genome of the pear (Pyrus bretschneideri Rehd.). Genome Res. 2013;23(2):396-408.

31. Verde I, Abbott AG, Scalabrin S, Jung S, Shu SQ, Marroni F, et al. The high-quality draft genome of peach (Prunus persica) identifies unique patterns of genetic diversity, domestication and genome evolution. Nat Genet. 2013;45(5):U447-87.

32. Zhang Q, Chen W, Sun L, Zhao F, Huang B, Yang W, et al. The genome of Prunus mume. Nat Commun. 2012;3:1318.

33. Leister D. Tandem and segmental gene duplication and recombination in the evolution of plant disease resistance genes. Trends Genet. 2004;20(3):116-22.

34. Peterson Gl, Masel J. Quantitative Prediction of Molecular Clock and K-a/K-s at Short Timescales. Mol Biol Evol. 2009;26(11):2595-603.

35. Tamura K, Peterson D, Peterson N, Stecher G, Nei M, Kumar S. MEGA5: Molecular Evolutionary Genetics Analysis Using Maximum Likelihood, Evolutionary Distance, and Maximum Parsimony Methods. Mol Biol Evol. 2011;28(10):2731-9.

36. Yang Z. PAML 4: phylogenetic analysis by maximum likelihood. Mol Biol Evol. 2007;24(8):1586-91.

37. Ohno S. Evolution by gene duplication. London: George Alien \& Unwin Ltd; 1970. Berlin, Heidelberg and New York: Springer-Verlag.

38. Cusack BP, Wolfe KH. When gene marriages don't work out: divorce by subfunctionalization. Trends Genet. 2007;23(6):270-2.

39. He X, Zhang J. Rapid subfunctionalization accompanied by prolonged and substantial neofunctionalization in duplicate gene evolution. Genetics. 2005;169(2):1157-64.

40. Xiao SY, Ellwood S, Calis O, Patrick E, Li TX, Coleman M, et al. Broad-spectrum mildew resistance in Arabidopsis thaliana mediated by RPW8. Science. 2001;291(5501):118-20.

41. Himmelreich R, Hilbert H, Plagens H, Pirkl E, Li BC, Herrmann R. Complete sequence analysis of the genome of the bacterium Mycoplasma pneumoniae. Nucleic Acids Res. 1996;24(22):4420-49.

42. Li WH, Gu ZL, Wang HD, Nekrutenko A. Evolutionary analyses of the human genome. Nature. 2001;409(6822):847-9.
43. Klenk HP, Clayton RA, Tomb JF, White O, Nelson KE, Ketchum KA, et al. The complete genome sequence of the hyperthermophilic, sulphate-reducing archaeon Archaeoglobus fulgidus. Nature. 1997;390(6658):364.

44. Kaul S, Koo HL, Jenkins J, Rizzo M, Rooney T, Tallon LJ, et al. Analysis of the genome sequence of the flowering plant Arabidopsis thaliana. Nature. 2000;408(6814):796-815.

45. Wagner A. Evolution of Gene Networks by Gene Duplications - a Mathematical-Model and Its Implications on Genome Organization. Proc Natl Acad Sci U S A. 1994;91(10):4387-91.

46. Hughes AL. The Evolution of Functionally Novel Proteins after Gene Duplication. Proc R Soc Lond B Biol Sci. 1994;256(1346):119-24.

47. Zhang JZ. Evolution by gene duplication: an update. Trends Ecol Evol. 2003;18(6):292-8.

48. Zhou T, Wang Y, Chen JQ, Araki H, Jing Z, Jiang K, et al. Genome-wide identification of NBS genes in japonica rice reveals significant expansion of divergent non-TIR NBS-LRR genes. Mol Genet Genomics. 2004;271(4):402-15.

49. Yang S, Feng Z, Zhang X, Jiang K, Jin X, Hang Y, et al. Genome-wide investigation on the genetic variations of rice disease resistance genes. Plant Mol Biol. 2006;62(1-2):181-93.

50. Lynch M, Conery JS. The evolutionary fate and consequences of duplicate genes. Science. 2000;290(5494):1151-5.

51. Wagner A. The fate of duplicated genes: loss or new function? Bioessays. 1998;20(10):785-8.

52. Roth C, Rastogi S, Arvestad L, Dittmar K, Light S, Ekman D, et al. Evolution after gene duplication: models, mechanisms, sequences, systems, and organisms. J Exp Zool B Mol Dev Evol. 2007;308(1):58-73.

53. Rastogi S, Liberles DA. Subfunctionalization of duplicated genes as a transition state to neofunctionalization. BMC Evol Biol. 2005;5:28.

54. Ding J, Zhang WL, Jing ZQ, Chen JQ, Tian DC. Unique pattern of R-gene variation within populations in Arabidopsis. Mol Genet Genomics. 2007;277(6):619-29.

55. Plocik A, Layden J, Kesseli R. Comparative analysis of NBS domain sequences of NBS-LRR disease resistance genes from sunflower, lettuce, and chicory. Mol Phylogenet Evol. 2004;31(1):153-63.

56. Yang J, Huang JX, Gu HY, Zhong Y, Yang ZH. Duplication and adaptive evolution of the chalcone synthase genes of dendranthema (Asteraceae). Mol Biol Evol. 2002;19(10):1752-9.

57. Zhang JZ, Zhang YP, Rosenberg HF. Adaptive evolution of a duplicated pancreatic ribonuclease gene in a leaf-eating monkey. Nat Genet. 2002;30(4):411-5.

58. Zhong Y, Jia YX, Gao Y, Tian DC, Yang SH, Zhang XH. Functional requirements driving the gene duplication in 12 Drosophila species. BMC Genomics. 2013;14:555.

59. Talbert PB, Bryson TD, Henikoff S. Adaptive evolution of centromere proteins in plants and animals. J Biol. 2004;3(4):18.

60. Tuskan GA, Difazio S, Jansson S, Bohlmann J, Grigoriev I, Hellsten U, et al. The genome of black cottonwood, Populus trichocarpa (Torr. \& Gray). Science. 2006;313(5793):1596-604.

61. Creelman RA, Mullet JE. Jasmonic acid distribution and action in plants: regulation during development and response to biotic and abiotic stress. Proc Natl Acad Sci. 1995;92(10):4114-9.

62. Parniske M, HammondKosack KE, Golstein C, Thomas CM, Jones DA, Harrison $\mathrm{K}$, et al. Novel disease resistance specificities result from sequence exchange between tandemly repeated genes at the Cf-4/9 locus of tomato. Cell. 1997;91(6):821-32.

63. Perazzolli M, Malacarne G, Baldo A, Righetti L, Bailey A, Fontana P, et al. Characterization of Resistance Gene Analogues (RGAs) in Apple (Malus x domestica Borkh.) and Their Evolutionary History of the Rosaceae Family. PLoS One. 2014;9(2):e83844.

64. Yue JX, Meyers BC, Chen JQ, Tian D, Yang S. Tracing the origin and evolutionary history of plant nucleotide-binding site-leucine-rich repeat (NBS-LRR) genes. New Phytologist. 2012;193(4):1049-63.

65. Liu JJ, Ekramoddoullah AKM. Root-specific expression of a western white pine PR10 gene is mediated by different promoter regions in transgenic tobacco. Plant Mol Biol. 2003;52(1):103-20.

66. Tarr DE, Alexander HM. TIR-NBS-LRR genes are rare in monocots: evidence from diverse monocot orders. BMC Res Notes. 2009;2:197.

67. Cannon SB, Zhu HY, Baumgarten AM, Spangler R, May G, Cook DR, et al. Diversity, distribution, and ancient taxonomic relationships within the TIR and non-TIR NBS-LRR resistance gene subfamilies. J Mol Evol. 2002;54(4):548-62. 
68. Malacarne G, Perazzolli M, Cestaro A, Sterck L, Fontana P, Van de Peer Y, et al. Deconstruction of the (paleo)polyploid grapevine genome based on the analysis of transposition events involving NBS resistance genes. PLoS One. 2012;7(1):e29762.

69. Punta M, Coggill PC, Eberhardt RY, Mistry J, Tate J, Boursnell C, et al. The Pfam protein families database. Nucleic Acids Res. 2012;40(D1):D290-301.

70. Price MN, Dehal PS, Arkin AP. FastTree 2-approximately maximum-likelihood trees for large alignments. PLoS One. 2010;5(3):e9490.

71. Larkin MA, Blackshields G, Brown NP, Chenna R, McGettigan PA, McWilliam H, et al. Clustal W and clustal X version 2.0. Bioinformatics. 2007;23(21):2947-8.

\section{Submit your next manuscript to BioMed Central} and take full advantage of:

- Convenient online submission

- Thorough peer review

- No space constraints or color figure charges

- Immediate publication on acceptance

- Inclusion in PubMed, CAS, Scopus and Google Scholar

- Research which is freely available for redistribution 